\title{
Prevalence and correlates of exchanging sex for money (gift) among private college students in Bahir Dar city, Northwest Ethiopia
}

\author{
Zelalem Alamrew $^{1}$, Worku Awoke ${ }^{1}$, Getachew Fikadie ${ }^{2}$, Bizuayhu Shimekaw ${ }^{3}$ \\ ${ }^{1}$ Departement of Public Health, College of Medicine and Health Sciences, Bahir Dar University, Ethiopia \\ ${ }^{2}$ Department of Public Health, College of Medicine and Health Sciences, Semera University, Ethiopia \\ ${ }^{3}$ Department of Public Health, College of Medical Sciences, Andinet Medical College, Dangla Ethiopia
}

\section{Email address:}

kzolam@gmail.com(Z.Alamrew),workuawo@yahoomail.com(W. Awoke),getsam2002@gmail.com(G. Fikadie), fbizuayhu@gmail.com(B. Shimekaw)

\section{To cite this article:}

Zelalem Alamrew, Worku Awoke, Getachew Fikadie, Bizuayhu Shimekaw. Prevalence and Correlates of Exchanging Sex for Money (Gift), among Private College Students in Bahir Dar City, Northwest Ethiopia. Clinical Medicine Research,

Vol. 2, No. 6, 2013, pp. 126-134. doi: 10.11648/j.cmr.20130206.13

\begin{abstract}
Background: Transactional sex is the practice of exchanging sex for financial or life style rewords; which has been associated with increased risk of HIV and others STD's. The aim of this study was to assess the prevalence and correlates of exchanging sex for money (gifts) among college students in Bahir Dar city. Methods: A cross sectional study was conducted in July 2012 among 790 students in eight private colleges in Bahir Dar city using multistage sampling technique. A pre-tested self-administered questionnaire was used. The data were analyzed in bivariate and multivariate logistic regression analysis with SPSS version 16 soft ware package. Results: About $27.8 \%$ of sexually active respondents of the study were reported to have exchanged sex for money (gift). Respondents reported unprotected sex were about 2 times more likely to exchange sex compared to those never did unprotected sex (AOR=1.85, 95\%CI: 1.07-8.78). The odds of exchanged sex was higher for students living in rented house with no family compared to those living with family (AOR= $1.78,95 \%$ CI: 1.03 -3.06), and for the students who used khat and shisha compared to those never took these substances $(\mathrm{AOR}=1.92,95 \% \mathrm{CI}: 1.10-3.33$ and $\mathrm{AOR}=3.14,95 \% \mathrm{CI}: 1.32-7.44)$ respectively. Moreover, the students visited night clubs more than two times a week were more than threefold risk of exchanging sex compared to those students never visited night clubs(AOR $=3.87,95 \% \mathrm{CI}: 1.71-8.78)$. Conclusion: This study revealed that $27.8 \%$ of sexually active respondents were ever exchanged sex and unprotected sex was associated with it, implying that receiving/paying money (gift) might interfere to negotiate condom use. Besides, several variables were associated with it, therefore, HIV/AIDS prevention programs need to give attention to exchanged sex.
\end{abstract}

Keywords: Exchanged Sex for Money (Gift), Sexual Risk Behaviours, HIV/AIDS, Adolescents and Young Adults, Ethiopia, Bahir Dar

\section{Background}

Adolescent and young adults' age is the time of experimentation and investigation but evidences suggested that youths are among the segment of population engaged in sexual risk behaviours such as exchanging sex for money (gift), multiple sexual partners and unprotected sex that could expose them at risk of HIV/AIDS [1]. Transactional sex is the practice of exchanging sex for financial or lifestyle reward; which has been strongly associated with increased risk of HIV and others sexually transmitted diseases [2].
Studies confirmed that a number of adolescent and young adults were involved in receiving/giving money from/for multiple partners in exchange for sexual favours. The reports further explained that exchanging sex for money is one of the riskiest forms of sexual encounters for HIV/AIDS other STD's [3].Evidences declared that receiving or giving something in exchange for sex in sub-Saharan Africa among sexually active adolescents is fairly common, especially in the case of unmarried ones [4]. Accordingly young people were involved in transactional sex due to different factors including peer pressure, substance use, to get school fees and other gifts [5].Besides a study in South Africa indicated 
that transactional sex was associated with socio-economic status, having multiple sexual partners and alcohol use. In addition, individuals who were more resistant to peer pressure to have sex were less likely to report exchanged sex with casual partners [6].Moreover, studies revealed that transactional sex was associated with elevated risk of HIV/AIDS infection among young people [7]. It is evident that HIV/AIDS affects all segments of the population but young people are largely affected by this disease and young females are largely affected than young males [8]. Several studies revealed that sexual activities in which young people engaged were risky which could result in HIV infection and other STD's [9]. According to Joint United Nations Program on HIV/AIDS (UNAIDS) 2010; millions of young people around the world confront a high risk of infection from HIV and other negative sexual outcomes as a result of behaviors that they adopt, or are forced to adopt [10]. Consequently today's youth have inherited a fatal legacy that is killing them, their family, teachers and their role models. Joint United Nations Program on HIV/AIDS(UNAIDS) 2011 report declared that globally out of estimated 2.7 million people newly infected with the virus about $41 \%$ were young people 15-24 years of age [11]. In Ethiopia according to Antenatal Care Sentinel surveillance (ANC) 2009, the prevalence of HIV/AIDS among young people of age 15-24 years was $2.6 \%$ [12]. Different studies suggested that many young people have got the necessary information from different sources with regard to HIV/AIDS, however; the major problem is to bring about behavioral change [3]. Organizations who are working on the prevention of the disease should give attention to sexual risk behaviours that could have a paramount help to control the spread of AIDS among youth. Private colleges in Ethiopia don't have accommodations for their students, so that most of them are living in the rented houses away from their supervising family and the majority them are from the poor rural farmers that have different social economical problems. Moreover, the current economic crises in the country particularly in the study area could have a role of college students to be engaged in exchanging sex for money to cover their learning fees and other expenses. Therefore, the objectives of the study was to explore the magnitude of exchanging sex for money (gifts) and associated factors for HIV/AIDS infection among college students in Bahir dar city. As to our knowledge, there is no published information on exchanging sex for money or gifts among college and university students in Ethiopia. So that this study provides paramount support for efforts intended at HIV/AIDS prevention and control programs among college and university students in the country.

\section{Methods}

Cross sectional quantitative study design was conducted among private college students of Bahir dar city in July 2012. This study was conducted in northwest part of Ethiopia at a distance of 563 kilometers from capital city (Addis Ababa) among regular private college students in Bahir Dar city. There are eight private colleges in city which have regular programs with different fields of study; these private colleges are among many colleges in Amhara regional state in Northwest of the country.

Bahir dar city is the capital city of Amhara regional state and is one of the cities in Ethiopia in which investment is rapidly growing and educational investment is one of those investments currently raising. Private colleges in the city host many students and are running different fields. According to the statistics obtained from the office of registrars of all colleges; there were a total of 3824 students enrolled in all programs, with 2218 female and 1606 male students.

All regular students of private colleges in Bahir Dar city enrolled in 2011/12 academic year and were attending their education in the day program were eligible for this study.

The sample size was determined using single population proportion formula. The proportion of exchanging sex for money (gift) was determined based on previous study done in Addis Ababa University 37\% [13]. The following assumptions were used: level of confidence 95\%, a 5\% marginal of error. Additional 10\% allowance for none response rate and correction for multi-stage sampling design effect 2 were considered. The final numbers of students included in the study were 790 .

The respondents were selected from target population through multistage sampling technique and Probability Proportionate to size of the students from each private colleges of in the City. The calculated sample size 790 was distributed in to each private college proportional to the size of their students. Departments were selected randomly from each college; then the sample size allocated to each college was distributed to each randomly selected department proportional to size of their students. The sample size allocated for each department again distributed to each year of study. Eventually, the required number of participants was chosen from each year of study by using simple random sampling methods from list of students.

Data were collected using self-administered structured questionnaires. Seven post graduate students as data collection facilitator and the principal investigator as supervisor were recruited during the field work. During the time of data collection, data collection facilitators were assigned on the selected sections. The students who were selected in the given section were given a questionnaire with an envelope and requested to read the consent form carefully to get informed verbal consent before they were enrolled in the study.

After getting informed consent, the data collection facilitators oriented the students how to fill the questionnaires properly, then after they told go ahead to start filling the questionnaires. Moreover the data collection facilitators assisted the students on questions that students might encounter a problem and the principal investigator coordinate the over all process of the data collection. At the end the respondents put the completed questionnaires in the 
box ready for collection of questionnaires themselves.

The questionnaire was initially prepared in English and translated in to local language Amharic in order to obtain the required information from the respondents and was translated back to English to check for any inconsistencies or distortions in the meaning of words and concepts. Data collection facilitators were trained for two days to make them familiar with the questionnaires; the way how to orient and guide the study participants in filling the questionnaire format. Pre-test was done among 40 randomly selected students from Bahir Dar polytechnic college. The data collection was completed within one day to avoid information contamination.

Data were double-entered onto the EPI-data Version 3.1 software by defining legal values for each variable and setting skip patterns. The double-entered data were validated and exported to SPSS version 16 software package.

Univarate and Bivarate analysis were computed to see the frequency distribution and to test whether there is association/difference/ between exchanging sex for money (gift) and selected independent variables respectively. Factors associated with exchanging sex for money at bivariate were identified and the variables with p-value of 0.20 and less were taken to multivariable analysis and the model was built with backward elimination. Finally, the p-values less than 0.05 were considered statistically significant.

Ethical clearance was obtained from ethical review committee of Bahir Dar University and communicated with regional health bureau before the time of data collection. Letter of permission was obtained from the health bureau and each college.

The confidentiality of information was maintained by excluding personal identifiers data were collected after securing informed consent and/or assent from every respondent.

\section{Results}

\subsection{Socio-Demographic Characteristics of the Study Population}

A total of 790 students completed the questionnaires of which 19 responses were excluded because of gross incompleteness and resulting a response rate of $97.6 \%$. Out of the total respondents $498(64.6 \%)$ were females. More than four fifth of the respondents $(84.7 \%)$ were never married. The mean \pm SD age of the study population was $21.46 \pm 2.441$ years. Slightly more than half of the respondents $(52.9 \%)$ were living alone in rented house and the rest were living with family. Three hundred eleven $(40.3 \%), 237(30.7 \%)$ and $223(28.9 \%)$ respondents were year one, two and three respectively. Moreover the study indicated that $36.8 \%, 27.2 \%, 33.1 \%$, and $2.9 \%$ of respondents were visiting religious institutions regularly, once or twice a week, some times and never visited religious institutions respectively. And more than $50 \%$ of the respondents (52.5\%) got pocket money below average 296 Ethiopian birr per month, while $180(23.3 \%)$ of the respondents got above 400 birr per month. Moreover $345(44.7 \%)$ and $159(20.6 \%)$ of the participants' mothers and fathers were Illiterate respectively; and 313 (61.5\%) participant's family monthly income was below the average 2523 Ethiopian birr while 118 (23.1\%) participants' families earn more than 3000 Ethiopian birr per month.

In terms of discussion on sexual issues between families and the students, $216(28 \%)$ and 143(18.5\%) of them were discussed on issues with their mothers and fathers respectively (Table 1).

Table 1. Socio demographic characteristics of college students in Bahir dar city, July 2012

\begin{tabular}{lll}
\hline Variables (N=771) & Categories & Total n (\%) \\
\hline \multirow{2}{*}{ Sex } & Male & $273(35.4)$ \\
& Female & $498(64.6)$ \\
Age & $15-19$ & $152(19.7)$ \\
& $20-24$ & $535(69.4)$ \\
Marital status & $>24$ & $84(10.9)$ \\
Living circumstance & Married & $118(15.3)$ \\
& Single & $653(84.7)$ \\
Years of study & Rented & $388(50.3)$ \\
& With family & $383(49.7)$ \\
& Year- I & $311(40.3)$ \\
Freq. of visiting religious sites & Year-II & $237(30.7)$ \\
& Year-III & $223(28.9)$ \\
& Regularly & $284(36.8)$ \\
& Onc/ twice a week & $210(27.2)$ \\
Mothers education level & Some times & $255(33.1)$ \\
& Never visit & $22(2.9)$ \\
& Illiterate & $345(44.7)$ \\
& Read and write & $245(31.8)$ \\
& $1-8$ grade & $89(11.5)$ \\
\hline
\end{tabular}




\begin{tabular}{|c|c|c|}
\hline Variables $(\mathrm{N}=771)$ & Categories & Total n (\%) \\
\hline \multirow{5}{*}{ Fathers educational level } & Illiterate & $159(20.6)$ \\
\hline & Read and write & $284(36.8)$ \\
\hline & $1-8$ grade & $115(14.9)$ \\
\hline & $9-12$ grade & $115(14.9)$ \\
\hline & Diploma \& above & $98(12.7)$ \\
\hline \multirow{3}{*}{ Discussion of sexual issues with mother } & Yes & $216(28)$ \\
\hline & No & $543(70.4)$ \\
\hline & I don't remember & $12(1.6)$ \\
\hline \multirow{3}{*}{ Discussion of sexual issues with father } & Yes & $143(18.5)$ \\
\hline & No & $616(79.9)$ \\
\hline & I don't remember & $12(1.6)$ \\
\hline
\end{tabular}

\subsection{Risk Related Factors for Exchanging sex for Money among College Students of Bahir Dar City}

Out of the total 771 respondents 326(42.3\%) were reported to have an intimate friend initiated sexual intercourse. Alcohol and Khat were the most frequently used substances. Accordingly out of the total respondents 194(25\%) alcohol, 139(18\%) Khat, 37(4.8\%) shisha and 15(1.9\%) were Cigarette users; of the total substance users 33 respondents $16(48.5 \%)$ males and $17(51.5 \%)$ females were reported to use regularly. One hundred sixty two
(54.5\%) males and 202(55.5\%) females were exposed to pornographic movies; of these respondents 104 (28.6\%) viewed once or twice a week and $185(50.8 \%)$ of them viewed occasionally. Besides, $153(19.2 \%)$ of total respondents were confessed to attend night clubs; of these night club attendants $28(18.3 \%)$ visited once a week and $44(28.7 \%)$ of them were attended more than two times a week. See table 2 for the detail.

Table 2. Percentage distributions of risk related factors for exchanging sex among college students in Bahir dar city, July 2012

\begin{tabular}{|c|c|c|c|}
\hline \multirow[t]{2}{*}{ Risk related factors $(\mathrm{N}=771)$} & \multicolumn{3}{|c|}{ Sex of the respondents } \\
\hline & Male & Female & Total n (\%) \\
\hline \multicolumn{4}{|l|}{ Peer pressure } \\
\hline Yes & $145(44.5$ & $181(55.5)$ & $326(42.3)$ \\
\hline No & $128(28.8)$ & $317(71.2)$ & $445(57.7)$ \\
\hline \multicolumn{4}{|l|}{ Khat use } \\
\hline Yes & $72(51.8)$ & $67(48.2)$ & $139(18)$ \\
\hline No & 201(31.8) & $431(68.2)$ & $632(82)$ \\
\hline \multicolumn{4}{|l|}{ Alcohol use } \\
\hline Yes & $100(51.5)$ & $94(48.5)$ & $194(25.2)$ \\
\hline No & $173(30)$ & $404(70)$ & $577(74.8))$ \\
\hline \multicolumn{4}{|l|}{ Shisha use } \\
\hline Yes & $21(56.8)$ & $16(43.2)$ & $37(4.8)$ \\
\hline No & $252(34.3)$ & $482(65.7)$ & $734(95.2)$ \\
\hline \multicolumn{4}{|l|}{ Frequency of using substances } \\
\hline Regularly & $16(48.5)$ & 17(51.5) & $33(4.3)$ \\
\hline Once or twice a week & $29(50.9)$ & $28(59.1)$ & $57(7.4)$ \\
\hline Some times & $91(51.4)$ & $86(48.6)$ & $177(22.96)$ \\
\hline Never use & $137(27.2)$ & $367(72.8)$ & $504(65.3)$ \\
\hline \multicolumn{4}{|l|}{ Viewed pornographic movies } \\
\hline Yes & $162(54.5)$ & $202(55.5)$ & $364(47.2)$ \\
\hline No & $111(27.3)$ & $296(72.7)$ & $407(52.8)$ \\
\hline \multicolumn{4}{|l|}{ Frequency of viewing porn } \\
\hline movies & $144(29.9)$ & $338(70.1)$ & $482(62.5)$ \\
\hline Never viewed & $48(46.2)$ & $56(53.8)$ & $104(13.5)$ \\
\hline $\begin{array}{l}\text { Once or twice a week } \\
\text { Some times }\end{array}$ & $81(43.8)$ & $104(56.2)$ & $185(24)$ \\
\hline \multicolumn{4}{|l|}{ Visited night club } \\
\hline Yes & $71(46.4)$ & $82(53.6)$ & $153(19.8)$ \\
\hline No & $202(32.7)$ & $416(67.3)$ & $618(80.2)$ \\
\hline \multicolumn{4}{|l|}{ Frequency of visiting night club } \\
\hline Never visit & $202(32.7)$ & $416(67.3)$ & $618((79.5)$ \\
\hline Some times & $40(49.4)$ & $41(50.6)$ & $81(10.5)$ \\
\hline Once a week & $8(28.6)$ & $20(71.4)$ & $28(3.63)$ \\
\hline More than two times a week & $23(52.3)$ & $21(47.7)$ & $44(5.7)$ \\
\hline
\end{tabular}




\subsection{Sexual Behaviours of the Study Participants of College Students in Bahir Dar city}

The findings of this study indicated that 391 (50.7\%) ever had sexual intercourse. The mean age at sexual commencement for both sexes was 18.7 years with standard deviation of 1.97 . One hundred nine $(27.8 \%)$ of respondents of the study $20(18.4 \%)$ males and $89(81.6 \%)$ females convinced to have paid and received money in exchange of sex respectively and $115(65 \%)$ males and 140(35\%) females, had sex with more than one sexual partner in past 12 months. Besides with regard to condom use, 231(59\%) sexually active respondents were reported to use condom consistently, however; $106(27 \%)$ and $44(11.3 \%)$ of sexually active respondents acknowledged to use condom occasionally and never during their sexual activities respectively. Among respondents who were not using condom consistently disclosed the reason why they failed to use was that, $44.4 \%$ reported condom decreases sexual pleasure, $28.7 \%$ described fear of side effects and $18.5 \%$ because of religious reason. Besides, this study declared that among respondents who didn't initiated sexual intercourse; about $59.7 \%$ reported delayed sex to wait until marriage, $30 \%$ fear of HIV/AIDS and $8.2 \%$ because of religious reason (Table 3)

Table 3. Sexual behaviours of college students in Bahir dar city, July 2012

\begin{tabular}{|c|c|c|c|}
\hline \multirow[t]{2}{*}{ Characteristics of Respondents } & \multicolumn{2}{|c|}{ Sex of respondents } & \multirow[t]{2}{*}{ Total n (\%) } \\
\hline & Male & Female & \\
\hline \multicolumn{4}{|l|}{ Ever had sexual intercourse $(n=771)$} \\
\hline Yes & $169(43.2)$ & $222(56.8)$ & $391(50.7)$ \\
\hline No & $104(27.4)$ & $276(72.6)$ & $380(49.3)$ \\
\hline \multicolumn{4}{|l|}{ Age at first sex(391) } \\
\hline$<18$ years & $68(36.6)$ & $118(63.4)$ & $186(47.6)$ \\
\hline$>=18$ years & $100(49)$ & $105(51)$ & $205(52.4)$ \\
\hline \multicolumn{4}{|l|}{ Ever had sex in the last 12 months $(n=391)$} \\
\hline Yes & $154(43.3)$ & $202(56.7)$ & $356(91)$ \\
\hline No & $15(42.9)$ & $20(57.1)$ & $35(9)$ \\
\hline Ever received or paid money(gift) to have sex(391) & $20(18.3)$ & $89(81.7)$ & $109(27.8)$ \\
\hline \multicolumn{4}{|l|}{ Number of sexual partner in the last 12 months(391) } \\
\hline One & $39(21.8)$ & $140(78.2)$ & $179(45.8)$ \\
\hline More than one & $115(65)$ & $62(35)$ & $177(45.3)$ \\
\hline \multicolumn{4}{|l|}{ Used condom in the first $\operatorname{sex}(n=391)$} \\
\hline Yes & $24(53.3)$ & 21(46.7) & $45(11.5)$ \\
\hline No & $143(41.9)$ & $198(58.1)$ & $341(87.2)$ \\
\hline \multicolumn{4}{|l|}{ Frequency of condom use $(n=391)$} \\
\hline Regularly & $102(44.2)$ & $129(55.8)$ & 231(59) \\
\hline Some times & $43(40.6)$ & $63(59.6)$ & $106(27)$ \\
\hline Never & $21(47.7)$ & $23(52.3)$ & $44(11.3)$ \\
\hline \multicolumn{4}{|l|}{ Reason not use condom $(n=254)$} \\
\hline Lack of information & $5(45.5)$ & $6(54.5)$ & $11(4.3)$ \\
\hline Cultural taboo & $4(40)$ & $6(60)$ & $10(3.93)$ \\
\hline Religious reason & $19(40.4)$ & $28(59.6)$ & $47(18.5)$ \\
\hline Fear of side effects & $25(34.2)$ & $48(65.8)$ & $73(28.7)$ \\
\hline Decreases pleasure/satisfaction & $49(43.4)$ & $64(56.6)$ & $113(44.4)$ \\
\hline \multicolumn{4}{|l|}{ Reason not have sex until study period $(n=380)$} \\
\hline Fear of AIDS/other STD'S & $41(35.7)$ & $74(64.3)$ & $115(30.3)$ \\
\hline Fear of family & $1(50)$ & $1(50)$ & $2(0.53)$ \\
\hline Because of religious reason & $12(38.7)$ & $19(61.3)$ & $31(8.2)$ \\
\hline Need to wait until marriage & $42(18.5)$ & $185(81.5)$ & $227(59.7)$ \\
\hline
\end{tabular}

\subsection{Logistic Regression Analysis between Exchanging Sex for Money (Gift) and Predictor Variables among Private College Students in Bahir Dar City}

The multivariate logistic regression analysis result indicated on table 4 that female students were more than seven times more likely to receive money compared to male students to pay money to have sex $(\mathrm{AOR}=7.78,95 \% \mathrm{CI}$ : 4.08-14.83). College students whose family were a way and living in rented houses were more likely to have exchanged sex for money compared to students who were living with their family ( $\mathrm{AOR}=1.78,95 \% \mathrm{CI}$ : $1.03-3.06$ ). Religiosity was the other predictor variable which showed significance difference with exchanging sex for money, students who were never visit religious sites and those visit sometimes were found to be about nine and seven times more likely to exchange sex for money compared to those visiting religious sites regularly $(\mathrm{AOR}=8.98,95 \% \mathrm{CI}$ : 2.45-32.92) and $\mathrm{AOR}=6.91, \quad 95 \% \mathrm{CI}: 2.95-16.14)$ respectively. Year of study of the respondents was the other predictor variable indicating that year three students had about three fold risk of exchanging sex for money 
compared to year one students $(\mathrm{AOR}=2.59$, 95\%CI: 1.20-5.59). Substance use such as Khat and shisha were the other predictor variables that showed significance difference with exchanging sex for money; students who were using Khat and shisha were about 2 and 3 times risk of exchanging sex for money compared to students who never took these substances $(\mathrm{AOR}=1.92,95 \% \mathrm{CI}: 1.10-3.33)$ and $\mathrm{AOR}=$ 3.14, 95\%CI: 1.32-7.44)) respectively. Besides, exchanging sex for money was associated with frequency of attending night club; students who visited night club more than two times a week had more than threefold risk of exchanging sex for money compared to students never visited(AOR $=3.87$, 95\%CI: $1.71-8.78)$. Moreover, the study indicated that students who reported unprotected sex in the last 12 months of their sexual activities were about 2 times more likely to have transactional sex compared to those never did unprotected $\operatorname{sex}(\mathrm{AOR}=1.85,95 \% \mathrm{CI}$ : 1.07-8.78).

Table 4. Comparison of exchanging sex for money by selected variables Private college students of Bahir dar city, July 2012

\begin{tabular}{|c|c|c|c|c|}
\hline \multirow{2}{*}{ Variable } & \multicolumn{2}{|c|}{ Exchanging sex for money } & \multicolumn{2}{|c|}{ OR(95\%CI) } \\
\hline & Yes & No & Crude & Adjusted \\
\hline \multicolumn{5}{|l|}{ Sex } \\
\hline Male & 20 & 253 & 1.00 & 1.00 \\
\hline Female & 89 & 409 & $2.753(1.653-4.583)$ & $7.78(4.08-14.83)$ \\
\hline \multicolumn{5}{|l|}{ Living condition } \\
\hline Rented & 77 & 311 & $2.716(1.750-4.215)$ & $1.78(1.03-3.06)$ \\
\hline With family & 32 & 351 & 1.00 & 1.00 \\
\hline \multicolumn{5}{|l|}{ Years of study } \\
\hline Year 1 & 12 & 299 & 1.00 & 1.00 \\
\hline Year 2 & 35 & 202 & $4.317(2.188-8.518)$ & $1.65(0.76-3.59)$ \\
\hline Year 3 & 62 & 161 & $9.595(5.024-18.328)$ & $2.59(1.20-5.59)$ \\
\hline \multicolumn{5}{|l|}{ Religiosity } \\
\hline Regularly & 8 & 276 & 1.00 & 1.00 \\
\hline Once or twice a week & 16 & 194 & $2.845(1.194-6.6780)$ & $2.63(1.04-6.61)$ \\
\hline Some times & 78 & 177 & $15.203(7.169-32.240)$ & $6.91(2.95-16.14)$ \\
\hline Never visit & 7 & 15 & $16.1(5.150-50.327)$ & $8.98(2.45-32.92)$ \\
\hline \multicolumn{5}{|l|}{ Monthly pocket per month } \\
\hline$<150$ birr & 25 & 211 & 1.00 & 1.00 \\
\hline $150-250$ birr & 17 & 150 & $0.96(0.50-1.83)$ & $0.63(0.29-1.38)$ \\
\hline $251-400$ birr & 29 & 159 & $1.54(0.87-2.73)$ & $1.08(0.54-2.25)$ \\
\hline$>400$ birr & 38 & 142 & $2.26(1.31-3.91)$ & $1.14(0.58-2.25)$ \\
\hline \multicolumn{5}{|l|}{ Peer pressure } \\
\hline Yes & 68 & 258 & $2.597(1.710-3.944)$ & $0.92(0.52-1.65)$ \\
\hline No & 41 & 404 & 1.00 & 1.00 \\
\hline \multicolumn{5}{|l|}{ Khat use } \\
\hline Yes & 42 & 97 & $3.651(2.347-5.680)$ & $1.92(1.10-3.33)$ \\
\hline No & 67 & 565 & 1.00 & 1.00 \\
\hline \multicolumn{5}{|l|}{ Shisha use } \\
\hline Yes & 16 & 21 & $5.251(2.645-10.426)$ & $3.14(1.32-7.44)$ \\
\hline No & 93 & 641 & 1.00 & 1.00 \\
\hline \multicolumn{5}{|l|}{ Alcohol use } \\
\hline Yes & 47 & 147 & $2.656(1.743-4.046)$ & $0.77(0.44-1.36)$ \\
\hline No & 62 & 515 & 1.00 & 1.00 \\
\hline \multicolumn{5}{|l|}{ Unprotected sex } \\
\hline Yes & 47 & 103 & $4.11(2.67-6.35)$ & $1.85(1.07-8.78)$ \\
\hline No & 62 & 559 & 1.00 & 1.00 \\
\hline \multicolumn{5}{|l|}{ Viewed sex movies } \\
\hline Yes & 74 & 290 & $2.712(1.764-4.171)$ & $1.11(0.63-1.97)$ \\
\hline No & 35 & 372 & 1.00 & 1.00 \\
\hline \multicolumn{5}{|l|}{ Frequency of viewing sex film } \\
\hline Never viewed & 47 & 435 & 1.00 & 1.00 \\
\hline Once or twice a week & 23 & 81 & $2.628(1.513-4.565)$ & $0.73(0.30-1.75)$ \\
\hline Some times & 39 & 146 & $2.472(1.554-3.932)$ & $0.86(0.38-1.92)$ \\
\hline \multicolumn{5}{|l|}{ Visited night club } \\
\hline Yes & 46 & 107 & $3.787(2.457-5.838)$ & $0.11(0.01-10.58)$ \\
\hline No & 63 & 555 & 1.00 & 1.00 \\
\hline \multicolumn{5}{|l|}{ Frequ. of visiting night club } \\
\hline Never visit & 61 & 557 & 1.00 & 1.00 \\
\hline Some times & 20 & 61 & $2.994(1.693-5.294)$ & $1.99(0.99-3.99)$ \\
\hline Once a week & 11 & 17 & $5.908(2.646-13.191)$ & $2.50(0.95-6.59)$ \\
\hline More than two times a week & 17 & 27 & $5.749(2.966-11.145)$ & $3.87(1.71-8.78)$ \\
\hline
\end{tabular}




\section{Discussion}

The aim of this study was to assess the prevalence and correlates of exchanging sex for money (gifts) for HIV/AIDS infection among private college students in Bahir dar city. Adolescents and young adults have increased interest in the opposite sex, highly concerned with sexual attractiveness and are frequently changing relationships [1]. Moreover, higher education students were engaged in risky sexual behaviours that could placed them at higher risk for HIV/AIDS [13, 14, 15]. Accordingly this study provides important information regarding sexual behavior of college students. The findings of this study indicated that $50.7 \%$ of the study respondents were sexually active and this is consistent with similar studies done in southern Ethiopia where the figure was 49\% [16] and 54\% in Uganda for both sexes [17]. According to this study the prevalence of exchanging sex for money (gift) was $27.8 \%$, and is line with study in Addis Ababa where exchanged sex among school adolescents was $20.6 \%$ [18], whereas our finding was not in accordance with a study among Addis Ababa university students where the prevalence of exchanged sex among sexually active respondents was $14.5 \%$ [19], and among south African young people the prevalence being 12.5\% [20]. The prevalence of exchanged sex for money (gift) in this study is relatively higher than the mentioned ones this could be because of private college students in Ethiopia were living in the rented houses where most of them were with no family supervision and they need to pay for college fees unlike governmental college and university students accommodated in the campus and learn free of payment.

The current study indicated that students who reported unprotected sex in the last 12 months of their sexual activities were about 2 times more likely to have exchanged sex compared to those never did unprotected sex ( $\mathrm{AOR}=1.85,95 \% \mathrm{CI}: 1.07-8.78)$, indicating that receiving/ paying/ money (gift) affects negotiations to condom use, in turn this is a serious obstacle to prevent HIV/AIDS and other sexually transmitted diseases and this is in line with a study conducted among university students in South Africa where transactional sex was a common practice and associated with unsafe and inequitable sexual practices [21].

Besides, the findings of our study declared that female students were more than seven times likely to receive money (gift) compared to male students to pay for sexual intimacy, this is line with a study among Addis Ababa university students and among unmarried adolescents in sub-Saharan African countries where more number of female adolescents were engaged in exchanged sex for money compared to males $[19,22]$. Whereas, our finding is not in accordance with a study among adolescents in USA where males were about two times more likely to be engaged in exchanged sex compared to their female counter parts [2].

According to our study substance use such as Khat and shisha were the other significant predictors of exchanging sex for money(gift); students who were using Khat and shisha were about two and three times risk of exchanging sex for money compared to students who never took these substances $(\mathrm{AOR}=1.92,95 \% \mathrm{CI}: 1.10-3.33)$ and $\mathrm{AOR}=3.14$, 95\%CI: 1.32-7.44)) respectively. This could be due to risk perception ability decreases with substance consumption; indicating that individuals who consume substances were more likely to get infected with HIV/AIDS and other sexually transmitted infections [23] and this is in line with other study where substance use was associated with exchanged sex [20].

\section{Strengths}

The Prevalence and correlates of exchanging sex for money among college students were identified.

The quality of the data was maintained by pretest of the questionnaires on similar population, prior training of the data collectors and supervisors. Besides, multistage sampling technique was employed to select the study subjects from all eight private colleges to minimize bias.

Moreover, appropriate tests were employed and findings were compared with related studies locally and internationally.

\section{Limitation}

Though transactional sex is one of sensitive issue of sexual behaviour, this study contains only quantitative component, it didn't triangulated qualitatively. In addition, despite self administrated questionnaire was used, which gave greater right to respond freely to get a valid data on this sexual sensitive issue; still social desirability bias might not be eliminated.

\section{Conclusions}

This study revealed that $27.8 \%$ of sexually active respondents of the study were ever exchanged sex for money (gift). Besides, unprotected sex was associated with transactional sex, implying that receiving/paying money (gift) might interfere to negotiate condom use. Moreover, religiosity, year of study of students, current living condition (living in rented house without family or living with family), khat and shisha use, and frequency of visiting night clubs were associated with exchanged sex; therefore, HIV/AIDS prevention programs need to give attention to exchanged sex.

\section{Acronyms}

ANC- Antenatal Care

EDHS- Ethiopian Demographic and Health Survey

EHNRI- Ethiopian Health and Nutrition Research Institute

FHI- Family Health International

STDs- Sexually Transmitted Diseases 


\section{Computing Interests}

Authors declared that they have no computing interests

\section{Author's Contribution}

ZA conceptualized the research problem, designed the study, conducted field work, collected data, and drafted the manuscript for publication.

WA was involved in Revision of the research proposal, supervision of the field work, data analysis and revision of the manuscript for publication.

GF Was involved in the conducted field work, collected data, analyzed data, and revision of the manuscript for publication

BS was involved in preparing the research proposal, field work, and revision of the manuscript. All authors of the manuscript have read and agreed to its content.

\section{Acknowledgements}

This study was funded by a grant from Bahir Dar University.

The authors are grateful to all private colleges in Bahir Dar city involved, data collectors and supervisors of the study. Finally our special gratitude goes to the participants of the study who shared their time to fill the questionnaires and give their genuine responses.

\section{References}

[1] Jenny Nicholson MSW Student, risky sexual behaviour among adolescents and young adults, University of North Carolina Chapel Hill, [Cited 2012 may 4]. Available from: http://www.docstoc.com/docs/38043379/

[2] Jessica M Edwards, Iritani B J, and Hallfors D D. Prevalence and correlates of exchanging sex for drugs or money among adolescents in the United States. Sex Transm Infect 2006; 82:354-358. doi: 10.1136/sti.2006.020693

[3] USAIDS AIDSTAR-One. Behavioral Interventions: Transactional and Age-disparate Sex in Hyperendemic Countries, [Cited 2012 December 10]. Available from:http://www.jamaicaobserver.com/news/No-to-sex-fordollar-13286102)

[4] AnnM. Moore1, Ann E. Biddlecom1, and Eliya M. Zulu2. Prevalence and meanings of exchange of money or gifts for sex in unmarried adolescent sexual relationships in sub-Saharan Africa. Afr J Reprod Health 2007; 11(3):44-61

[5] Wamoyi et al., Transactional sex amongst young people in rural northern Tanzania: an ethnography of young women's motivations and negotiation. Reproductive Health 2010, 7:2

[6] Kristin L Dunkle. Transactional sex and economic exchange with partners among young South African men in the rural Eastern Cape: prevalence, predictors, and associations with gender-based violence. Soc Sci Med. 2007; 65(6): $1235-1248$.
[7] Dunkle K L, Jewkes R K, Brown H C, McIntyre J A, and Gray G E. Prevalence of transactional sex in an antenatal clinic population in South Africa. The $14^{\text {th }}$ International AIDS Conference ; 2002

[8] WHO/UNICE. Global Consultation on Strengthening the Health Sector Response to Care, Support, Treatment and Prevention for Young People Living with HIV; Blantyre Malawi, November, 2006

[9] Rweng.M. Sexual Risk Behavior among Young People in Bamenda Cameroon. International Family Planning Perspectives 2000; 26(3):118-130.

[10] Young People Most at Risk of HIV: A Meeting Report and Discussion Paper from the Interagency Youth Working Group, the Joint United Nations Programme on HIV/AIDS (UNAIDS) Inter-Agency Task Team on HIV and Young People, and FHI. Research Triangle Park, NC: FHI, 2010.

[11] Joint United Nations Programme on HIV AIDS (UNAIDS). Global HIV/AIDS response, epidemic update and health sector progress towards universal access, progress report 2011.

[12] Report on the 2009 Round Antenatal Care Sentinel HIV Surveillance in Ethiopia. Ethiopian Health and Nutrition Research Institute (EHNRI); Addis Ababa, August, 2011

[13] Nigatu R, Seman K. Attitudes and practices on HIV preventions among students of higher education institutions in Ethiopia. Educational Research 2011; 2(2): 828-840

[14] Diana Flannery and Lyndall Ellingson. Sexual Risk Behaviors among First Year College Students. Californian Journal of Health Promotion 2003;1(3) : 93-104

[15] Sunmola AM. Evaluating the sexual behaviour, barriers to condom use and its actual use by university students in Nigeria. AIDS Care 2005; 17(4): 457-465

[16] Zerai K . Sexual Experiences and their Correlates Among Jimma University Students, Jimma, Ethiopia. Ethiop. J. Health Sci 2002; 15(1): 21-29

[17] Najjumba M.I, Ntozi.J, Ahimbisibwe E.F, Odwee. J and Ayiga Natal. Risk perception and condom use in Uganda. African population studies 2003; 18 (1): 68-80

[18] Amsale C and Yemane B. Peer Pressure Is the Prime Driver of Risky Sexual Behaviors among School Adolescents in Addis Ababa, Ethiopia. World Journal of AIDS 2012; 2: $159-164$

[19] Nigatu Regassa, Seman Kedir. Attitudes and practices on HIV preventions among students of higher education institutions in Ethiopia: The case of Addis Ababa University. Educational Research(ISSN: 2141-5161) 2011; 2(2) : 828-840

[20] Kristin L, Rachel J, Mzikazi N, Nwabisa J, Jonathan L, Yandisa $\mathrm{S}$ et al. Transactional sex and economic exchange with partners among young South African men in the rural Eastern Cape. Soc Sci Med. 2007 September; 65(6): 1235-1248. doi:10.1016/j.socscimed.2007.04.029.

[21] Tamara S, Lindsay C and Tania V. Narratives of transactional sex on a university campus. Culture, Health \& Sexuality: An International Journal for Research, Intervention and Care 2012; 14(4): 435-447 
134 Zelalem Alamrew et al.: Prevalence and Correlates of Exchanging Sex for Money (Gift), among Private College Students in Bahir Dar City, Northwest Ethiopia

[22] Ann M. M, Ann E.B, and Eliya M.Z. Prevalence and meanings of exchange of money or gifts for sex in unmarried adolescent sexual relationships in sub-Saharan Africa. Afr J Reprod Health 2007; 11(3):44-61
[23] Alcohol Use and Sexual Risk Behaviour: A Cross-Cultural Study in Eight Countries. World Health Organization Geneva 2005. 